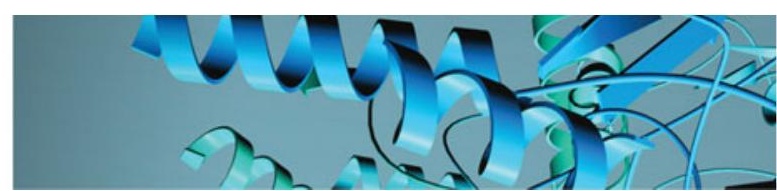

\title{
CORRIGENDUM
}

\section{Photosystem II: the water splitting enzyme of photosynthesis and the origin of oxygen in our atmosphere - CORRIGENDUM}

James Barber

Quarterly Reviews of Biophysics (2016), 49, e16, page $1 \quad$ doi:10.1017/S0033583516000123

Doi: 10.1017/S0033583516000093 First published online by Cambridge University Press, 1 August 2016.

The original version of this article was published with an incorrect title. The correct title is: Photosystem II: the water splitting enzyme of photosynthesis and the origin of oxygen in our atmosphere.

\section{Reference}

BARBER, James (2016). 'Photosystem II: the water splitting enzyme of photosynthesis and the origin of oxygen in our atmosphere'. Quarterly Reviews of Biophysics, 49, e14. doi:10.1017/S0033583516000093. 